\title{
Wild blueberry (Vaccinium angustifolium)-enriched diet improves dyslipidaemia and modulates the expression of genes related to lipid metabolism in obese Zucker rats
}

\author{
Stefano Vendrame, Allison Daugherty, Aleksandra S. Kristo and Dorothy Klimis-Zacas* \\ Department of Food Science and Human Nutrition, University of Maine, 5735 Hitchner Hall, Orono, ME 04469, USA
}

(Submitted 28 January 2013 - Final revision received 2 May 2013 - Accepted 6 June 2013 - First published online 6 August 2013)

\begin{abstract}
The present study investigated the potential of a wild blueberry (WB)-enriched diet to improve blood lipid profile and modulate the expression of genes related to lipid homeostasis in obese Zucker rats (OZR), a model of the metabolic syndrome with severe dyslipidaemia. For this purpose, twenty OZR and twenty lean Zucker rats (LZR; controls) were placed either on a control (C) or an $8 \%$ WB diet for 8 weeks. Plasma total cholesterol (TC), HDL-cholesterol and TAG concentrations were determined. The relative expression of six genes involved in lipid metabolism was also determined in both the liver and the abdominal adipose tissue (AAT). Plasma TAG and TC concentrations were significantly lower in the OZR following WB consumption (4228 (SEM 471) and 2287 (sEm 125) mg/l, respectively) than in those on the $\mathrm{C}$ diet $(5475$ (SEm 315) and 2631 (SЕм 129) mg/l, $P<0.05$ ), while there was no change in HDL-cholesterol concentration. No significant effects were observed for plasma lipids in the LZR. Following WB consumption, the expression of the transcription factors PPAR $\alpha$ and PPAR $\gamma$ in the OZR was increased in the AAT, while that of sterol regulatory element-binding protein 1 (SREBP-1) was decreased in the liver and AAT. The expression of fatty acid synthase was significantly decreased in both the liver and AAT and that of ATP-binding cassette transporter 1 was increased in the AAT following WB consumption. In conclusion, WB consumption appears to improve lipid profiles and modulate the expression of key enzymes and transcription factors of lipid metabolism in severely dyslipidaemic rats.
\end{abstract}

Key words: Wild blueberries: Dyslipidaemia: Anthocyanins: PPAR: Sterol regulatory element-binding protein 1

CHD continues to be the leading cause of death, both in the USA and worldwide, with dyslipidaemia being a major risk of acute cardiovascular events ${ }^{(1)}$. Other intimately related risk factors, such as central adiposity, insulin resistance, glucose intolerance and hypertension, tend to co-manifest with dyslipidaemia, creating a dysfunctional state referred to as the metabolic syndrome that dramatically increases the risk of type 2 diabetes and $\mathrm{CHD}^{(2)}$.

Several lines of evidence show that diet is one of the most manageable factors for preventing the metabolic syndrome and its progression in the human population ${ }^{(3)}$.

The obese Zucker rat (OZR) is a valid experimental model for the human metabolic syndrome due to its similarities with the characteristics and progression of this condition in humans ${ }^{(4)}$. OZR have impaired satiety reflex and chronic elevation in food intake, increased activity of the adipose lipoprotein lipase (LPL), defective catabolism of chylomicrons and overproduction of hepatic $\mathrm{VLDL}^{(5)}$. By the age of 8 weeks, they develop obesity and a profound dyslipidaemic state, with hypertriacylglycerolaemia and hypercholesterolaemia ${ }^{(4)}$.

Wild blueberries (Vaccinium angustifolium) are commercially available berries containing high levels of antioxidant polyphenols, mostly anthocyanins ${ }^{(6)}$.

Our previous studies have demonstrated the potential of wild blueberries to enhance vasorelaxation pathways and reduce vasoconstriction in Sprague-Dawley ${ }^{(7)}$ and spontaneously hypertensive rats ${ }^{(8)}$.

Anthocyanins have been shown in vitro to affect the expression of genes involved in lipid metabolism, including fatty acid synthase, LPL and ATP-binding cassette transporter 1 (ABCA1 $^{(9-11)}$. Anthocyanins have also been shown to modulate the transcriptional activities of different nuclear receptors that control lipid homeostasis, including PPAR in rats and sterol regulatory element-binding proteins (SREBP) in mice ${ }^{(12-14)}$.

In the present study, we used the OZR model of the metabolic syndrome to study the effects of a wild

Abbreviations: AAT, abdominal adipose tissue; ABCA1, ATP-binding cassette transporter 1; C, control diet; LPL, lipoprotein lipase; LZR, lean Zucker rat; OZR, obese Zucker rat; SREBP, sterol regulatory element-binding protein; TC, total cholesterol; WB, wild blueberry-enriched diet. 
blueberry-enriched diet on plasma lipid profile and the genetic expression of selected enzymes and transcription factors that play crucial roles in lipid and cholesterol homeostasis.

\section{Experimental methods}

\section{Zucker rats}

A total of twenty male OZR $(f a / f a)$ and twenty male LZR $(\mathrm{Fa} / \mathrm{Fa})$ were purchased from Charles River Laboratories at 8 weeks of age and randomly assigned to either a control (C) or a wild blueberry-enriched (WB) diet for 8 weeks.

The rats were housed in individual mesh-bottomed cages in a room at $22^{\circ} \mathrm{C}$ and under a $12 \mathrm{~h}$ light $-12 \mathrm{~h}$ dark cycle. Food consumption was recorded daily, and the rats were weighed weekly. The experimental protocol was approved by the University of Maine Institutional Animal Care and Use Committee.

\section{Wild blueberries}

Wild blueberries were provided as a composite (Wyman's), freeze-dried powder following standard procedures (FutureCeuticals), vacuum-packed in individual plastic bags, stored at $-20^{\circ} \mathrm{C}$ and used within 3 months.

The concentration of anthocyanins and profile of the WB powder were determined using liquid chromatography/MS as described previously ${ }^{(15)}$. Total phenolic content was determined spectrophotometrically using the Folin-Ciocalteu method $^{(16)}$. Fibre content was determined using the AOAC International method $991.43^{(17)}$. Sugar content was determined using ultra-HPLC/MS, as described previously ${ }^{(18)}$.

\section{Diets}

Diets were prepared from purified ingredients, stored at $4{ }^{\circ} \mathrm{C}$ and used within 1 week. The $\mathrm{C}$ diet was prepared by mixing $691 \mathrm{~g} / \mathrm{kg}$ of dextrose, $200 \mathrm{~g} / \mathrm{kg}$ of egg-white solids, $60 \mathrm{~g} / \mathrm{kg}$ of maize oil, $35 \mathrm{~g} / \mathrm{kg}$ of mineral mix (AIN-93M), $10 \mathrm{~g} / \mathrm{kg}$ of vitamin mix (AIN-93), $4 \mathrm{~g} / \mathrm{kg}$ of DL-methionine and $0.002 \mathrm{~g} / \mathrm{kg}$ of biotin. It provided approximately $71 \%$ carbohydrate, $6 \%$ fat, $17 \%$ protein and $1687 \mathrm{~kJ} / 100 \mathrm{~g}$. The WB diet was of the same composition, except for the incorporation of an $8 \% \mathrm{WB}$ powder substituting for an equivalent amount of dextrose. It provided approximately $68 \%$ carbohydrate, $6 \%$ fat, $17 \%$ protein, $1.5 \%$ fibre, $0 \cdot 12 \%$ anthocyanin and $1645 \mathrm{~kJ} / 100 \mathrm{~g}$. On using the body surface area calculation $^{(19)}$, this amount would be equivalent to approximately two cups of fresh WB per $\mathrm{d}$ for an average human adult.

\section{Tissue collection}

At 16 weeks of age, after an overnight fast, the rats were anaesthetised with $95 \% \quad \mathrm{CO}_{2}-5 \% \quad \mathrm{O}_{2}$ for approximately $2 \mathrm{~min}$ and exsanguinated by cardiac puncture. Blood was immediately collected for plasma separation and storage at $-80^{\circ} \mathrm{C}$ until further analysis. The liver and abdominal adipose tissue (AAT) were excised, snap-frozen in liquid $\mathrm{N}_{2}$ and stored at $-80^{\circ} \mathrm{C}$ for subsequent mRNA isolation.

\section{Blood lipid profile}

Plasma samples were analysed for TAG, total cholesterol (TC) and HDL-cholesterol concentrations. TAG and TC concentrations were measured using colorimetric kits (Cayman no. 10010303 and Cayman no. 10007640). HDL-cholesterol concentration was measured using a fluorometric kit (BioVision no. K613-100). Non-HDL-cholesterol (LDL + VLDL) concentration was calculated by subtracting HDL-cholesterol from TC.

\section{Hepatic and AAT mRNA isolation and reverse transcription}

Hepatic mRNA was isolated from frozen samples using the RNeasy Mini Kit (Qiagen no. 74104), while ATT mRNA was isolated using the RNeasy Lipid Tissue Mini Kit (Qiagen no. 74804). Absorbance at 260 and $280 \mathrm{~nm}$ was measured using UV-transparent cuvettes to estimate quantity and control for the quality of the isolated mRNA. The samples of mRNA were subsequently retro-transcribed to cDNA using the QuantiTect Reverse Transcription Kit (Qiagen no. 205313).

\section{Real-time RT-PCR}

The reverse transcription product was subjected to two-step, real-time, RT-PCR amplification on a quantitative PCR System (Bio-Rad CFX96) using SYBR Green master mix (SSoFast EvaGreen, Bio-Rad no. 172-5202; BioRad Laboratories) and commercially available rat-specific primer sequences (Qiagen) targeting the following genes: PPAR $\alpha$ (Ppara, RefSeq NM013196); PPAR $\gamma$ (Pparg, RefSeq NM001145366, NM001145367, NM013124); sterol regulatory element-binding protein 1 (Srebf1, RefSeq XM001075680, XM213329); fatty acid synthase (Fasn, RefSeq NM017332); LPL ( $L p l$, RefSeq NM012598); ABCA1 (Abca1, RefSeq NM178095). A standard curve was constructed for all the primers on a pooled sample of complementary DNA, and the efficiency was found to be in the $90-100 \%$ range. For each primer and tissue, the analysis was performed in triplicate with a reaction volume of $20 \mu \mathrm{l}$ per well $(1.5 \mu \mathrm{l}$ reverse transcription product, $10 \mu \mathrm{l}$ SYBR Green mix, $2 \mu \mathrm{l}$ primers and $6.5 \mu \mathrm{l}$ RNase-free water). After enzyme activation $\left(95^{\circ} \mathrm{C}\right.$ for $\left.30 \mathrm{~s}\right)$, forty-five amplification cycles were performed (denaturation at $95^{\circ} \mathrm{C}$ for $2 \mathrm{~s}$ and annealing/extension at $60^{\circ} \mathrm{C}$ for $5 \mathrm{~s}$ ) followed by the construction of a melting curve $\left(75-95^{\circ} \mathrm{C}\right)$ to ensure the specificity of amplification. The relative expression of the genes of interest was determined by the $\Delta \Delta \mathrm{Ct}$ method $^{(20)}$ relative to that of the housekeeping gene $\beta$-actin. The results are reported as fold variation compared with those of lean Zucker rats (LZR) on the $\mathrm{C}$ diet.

\section{Statistical analysis}

Results for each marker were analysed using a two-way ANOVA, with diet (WB $v$. C) and animal model (OZR and LZR) as independent factors. Significant main effects and interactions were further evaluated by means of Tukey's honestly significant difference post hoc test. Statistical analysis was performed using $\mathrm{R}$ statistical software version 2.15.1 
( $\mathrm{R}$ Foundation for Statistical Computing). The results are expressed as means with their standard errors, and they were considered significant at $P<0 \cdot 05$.

\section{Results}

\section{Food intake and animal weight}

Average daily food intake was significantly higher in the OZR (30.1 (sem 2.6) g) than in the LZR (24.4 (SEm 2.3) g, $P<0.05$ ), but without statistically significant differences between the WB and $\mathrm{C}$ groups. In the OZR, both average weight gain during the experiment (270 (SEM 46) g) and average body weight during the time of killing ( 583 (SEM 72) g) were significantly higher than those in the LZR (168 (SEM 17) and 383 (sEm 20)g, respectively, $P<0.05$ ), but without statistically significant differences between the WB and C groups throughout the feeding period.

\section{Wild blueberry powder composition}

The total anthocyanin content of the WB powder was $1.5 \%$ (w/w), with malvidin-3-galactoside, peonidin-3-glucoside and delphinidin-3-glucoside being the most abundant anthocyanins. Total phenolic content (gallic acid equivalents) was $4.4 \%(\mathrm{w} / \mathrm{w})$. The most abundant individual phenolic compound was chlorogenic acid $(510 \mathrm{mg} / 100 \mathrm{~g})$. Total fibre content was $18 \%(\mathrm{w} / \mathrm{w})(15 \cdot 2 \%$ insoluble fibre and $2 \cdot 8 \%$ soluble fibre). Total sugar content was $68 \cdot 4 \%(\mathrm{w} / \mathrm{w})(35 \cdot 2 \%$ glucose and $33 \cdot 2 \%$ fructose).

\section{Blood lipid profile}

Plasma TAG, TC and HDL-cholesterol concentrations were significantly higher in the OZR than in the LZR, independent of the diet (Table 1). Within the OZR, plasma TAG and TC concentrations were significantly lower in the WB group than in the control group, whereas no differences were observed for HDL-cholesterol concentration. Within the LZR, no statistically significant differences were observed for any of the abovementioned parameters, although the trends were similar to those observed in the obese group.

\section{Hepatic gene expression}

The expression of fatty acid synthase was dramatically higher in the OZR than in the LZR, independent of the diet (Fig. 1). The expression of SREBP-1 and PPAR $y$ was also higher in the OZR, while that of ABCA1 and PPAR $\alpha$ was not statistically different in the OZR and LZR. The expression of SREBP-1 and fatty acid synthase was significantly decreased in the OZR on the WB diet. Variations in the levels of other markers were not statistically significant.

\section{Genetic expression in the abdominal adipose tissue}

The expression on PPAR $\alpha$, PPAR $\gamma$ and ABCA1 was not statistically different in the LZR and OZR, independent of the diet (Fig. 2). The expression of fatty acid synthase, LPL and SREBP-1 was higher in the OZR than in the LZR. Following WB consumption, the expression of the transcription factors PPAR $\alpha$ and PPAR $\gamma$ was increased in the AAT in both the OZR and LZR, while that of SREBP-1 was decreased. The expression of fatty acid synthase was significantly decreased in both the OZR and LZR, while that of LPL was increased in the LZR only. The expression of ABCA1 was increased in both the OZR and LZR.

\section{Discussion}

The present study investigated the ability of a WB-enriched diet to improve parameters related to the pathogenesis of the metabolic syndrome, focusing, in particular, on blood lipid profile and expression of genes related to lipid metabolism in the liver and AAT. The experimental model used was the OZR, in which the development of the metabolic syndrome and its associated abnormalities is very similar to that observed in humans ${ }^{(4)}$.

The present study is the first to report on a significant TAG-lowering effect of WB in vivo. The overall improvement in blood lipid profile observed in the OZR following WB consumption with both plasma TAG and cholesterol concentrations being significantly decreased is consistent with previous animal studies reporting an association between blueberry consumption and lowered cholesterol and TAG concentrations. The consumption of 1,2 and

Table 1. Fasting plasma concentrations of TAG and cholesterol in lean Zucker rats (LZR) and obese Zucker rats (OZR) following the consumption of a control (C) or a wild blueberry diet (WB)

(Mean values and standard deviations, $n$ 10)

\begin{tabular}{|c|c|c|c|c|c|c|c|c|}
\hline & \multicolumn{2}{|c|}{ LZR-C } & \multicolumn{2}{|c|}{ LZR-WB } & \multicolumn{2}{|c|}{ OZR-C } & \multicolumn{2}{|c|}{ OZR-WB } \\
\hline & Mean & SEM & Mean & SEM & Mean & SEM & Mean & SEM \\
\hline TAG (mg/l) & $864^{a}$ & 118 & $981^{\mathrm{a}}$ & 95 & $5475^{\mathrm{c}}$ & 315 & $4228^{b}$ & 471 \\
\hline Total cholesterol (mg/l) & $1011^{a}$ & 87 & $928^{a}$ & 50 & $2631^{\mathrm{c}}$ & 129 & $2287^{b}$ & 125 \\
\hline HDL-cholesterol (mg/l) & $518^{\mathrm{a}}$ & 54 & $530^{\mathrm{a}}$ & 36 & $1381^{b}$ & 113 & $1332^{b}$ & 89 \\
\hline Non-HDL-cholesterol $(\mathrm{mg} / \mathrm{l})^{\star}$ & $494^{\mathrm{a}}$ & 37 & $398^{\mathrm{a}}$ & 44 & $1271^{\mathrm{c}}$ & 24 & $954^{\mathrm{b}}$ & 77 \\
\hline
\end{tabular}

a,b,c Mean values within a row with unlike superscript letters were significantly different $(P<0.05)$

${ }^{*}$ Calculated by difference. 
(A)

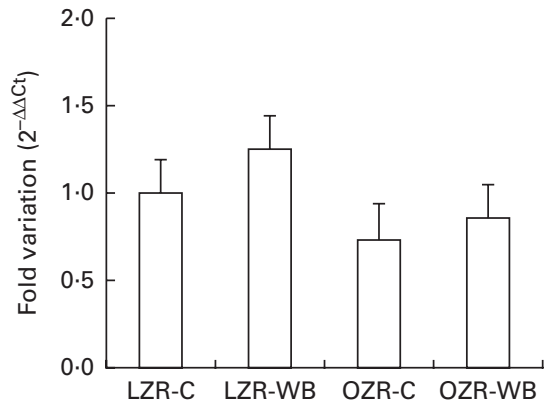

(B)

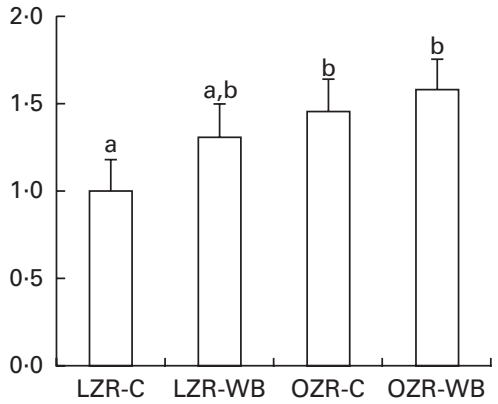

(C)

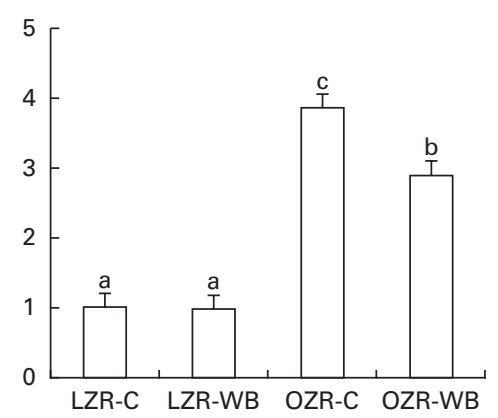

(D)

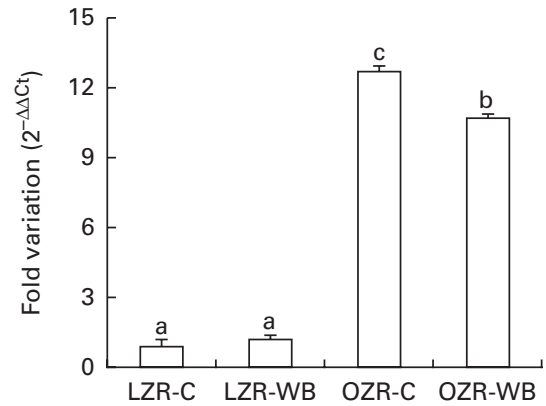

(E)

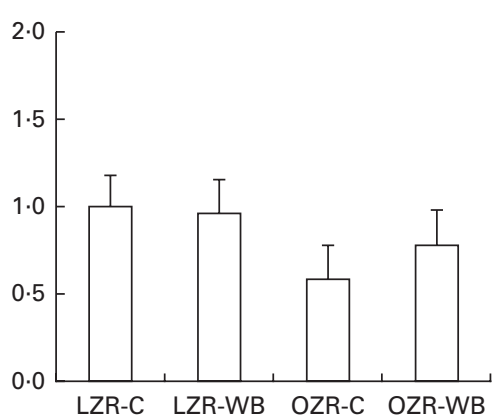

Fig. 1. Relative expression of the genes related to lipid metabolism in the liver of lean Zucker rats (LZR) and obese Zucker rats (OZR): (A) PPAR $;$; $(B) P P A R \gamma$; (C) sterol regulatory element-binding protein 1; (D) fatty acid synthase; (E) ATP-binding cassette transporter A1. Values are means $(n$ 10), with their standard errors represented by vertical bars. ${ }^{a, b, c}$ Mean values within a row with unlike letters were significantly different $(P<0.05)$. C, control diet; WB, wild blueberry diet.

$4 \%$ blueberry-supplemented diets for 8 weeks significantly reduced not only LDL-cholesterol concentration but also HDL-cholesterol concentration in pigs ${ }^{(21)}$, while supplementation with a $2 \%$ highbush blueberry powder for $90 \mathrm{~d}$ significantly reduced serum TAG concentration in OZR and LZR fed a high-fat diet ${ }^{(14)}$.

In the present study, the decrease in TC concentration was accounted for by decreased LDL-cholesterol and/or VLDL-cholesterol concentrations, while no change was observed in HDL-cholesterol concentration, a significant finding considering the importance of maintaining or increasing HDL-cholesterol concentration with dietary interventions. Overall, the observed changes in lipid profiles following the consumption of the WB diet in the OZR appear to be markedly beneficial, considering that high plasma TC, non-HDL-cholesterol and TAG concentrations are implicated in the pathogenesis of atherosclerosis and recognised risk factors of $\mathrm{CHD}^{(1)}$.

It must be noted that recent studies have not confirmed this effect in humans, possibly due to the high inter-individual variability. An intervention with $50 \mathrm{~g}$ freeze-dried highbush blueberries administered daily for 8 weeks, while showing a reduction in blood pressure and oxidised LDL concentration, did not lead to significant variations in lipid profiles in obese subjects with the metabolic syndrome ${ }^{(22)}$. Another interventional study on individuals at a risk of developing CVD has also failed to report any effects on lipid profiles after 6 weeks of consumption of a drink providing $25 \mathrm{~g}$ freeze-dried $\mathrm{WB}^{(23)}$, probably due to the already low baseline values. Purified anthocyanins (320 mg twice a day for 24 weeks) have been shown to significantly decrease LDL-cholesterol concentration and increase HDL-cholesterol concentration in hypercholesterolaemic individuals, without affecting TC and TAG concentrations ${ }^{(24)}$.

To better understand the metabolic effects of WB consumption, we focused on the genetic expression of selected enzymes and transcription factors that regulate lipid and cholesterol homeostasis.

Anthocyanins such as cyanidin-3-glucoside have been shown in vitro to regulate the expression and activity of key enzymes involved in TAG and cholesterol metabolism, including LPL ${ }^{(9)}$, fatty acid synthase ${ }^{(10)}$ and ABCA1 ${ }^{(11)}$, which could explain the observed effects of blueberry consumption on lipid profiles.

In the present study, the expression of LPL in the AAT was found to be almost threefold higher in the OZR than in the LZR. Following the consumption of the WB diet, the expression of LPL was significantly up-regulated in the LZR, reflecting the up-regulation of the expression of PPAR $\alpha$ observed in the AAT. Indeed, the expression of LPL is under the transcriptional control of PPAR $\alpha$ and promotes the release of fatty acids from circulating lipoproteins and their subsequent cellular uptake ${ }^{(25)}$.

The expression of fatty acid synthase, which is under the transcriptional control of SREBP- $1 c^{(26)}$, was more than twelvefold higher in the liver of the OZR and threefold higher in the AAT of the OZR than in those of the LZR. Following the consumption of the WB diet, the expression 
(A)

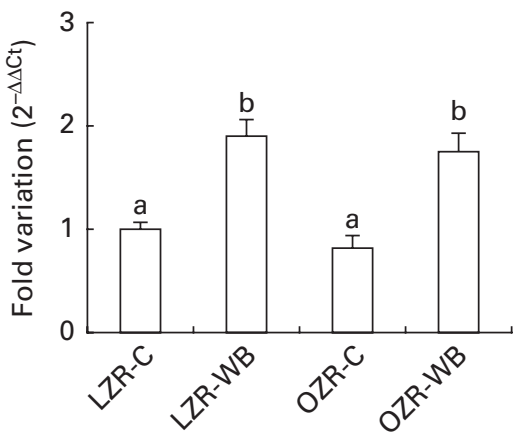

(D)

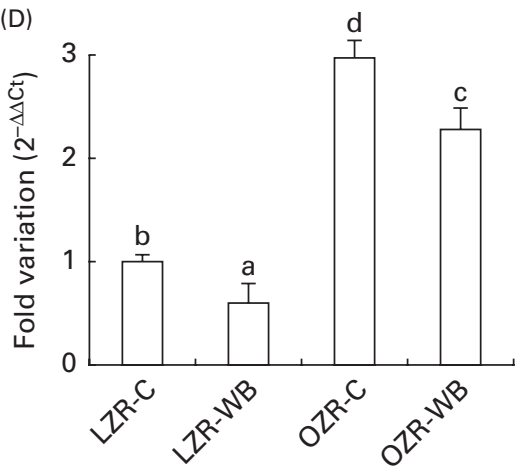

(B)

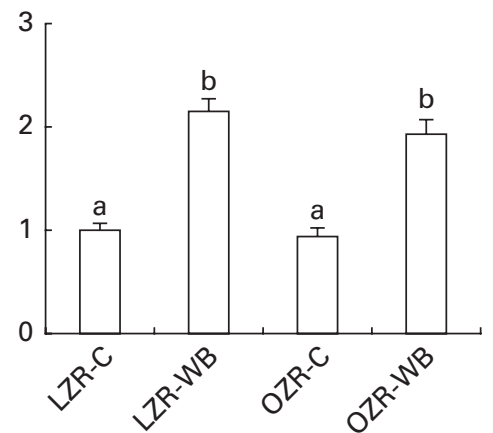

(E)

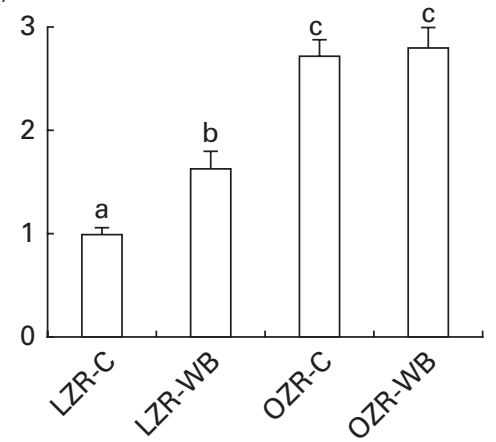

(C)

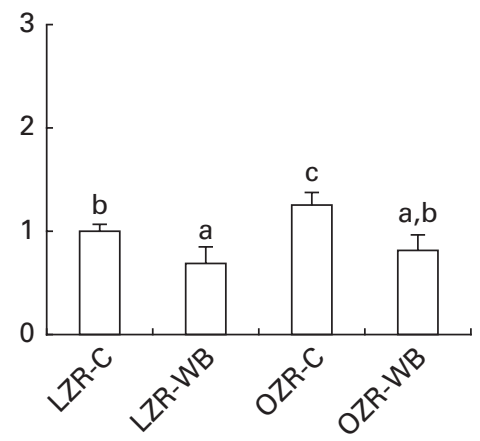

(F)

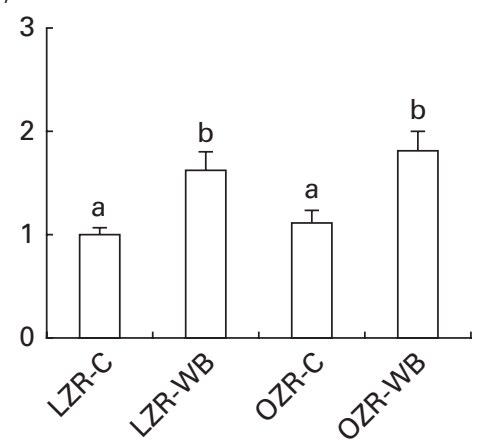

Fig. 2. Relative expression of the genes related to lipid metabolism in the abdominal adipose tissue of lean Zucker rats (LZR) and obese Zucker rats (OZR): (A) PPAR $\alpha$; (B) PPAR ; (C) sterol regulatory element-binding protein 1; (D) fatty acid synthase; (E) lipoprotein lipase; (F) ATP-binding cassette transporter A1. Values are means $(n 10)$, with their standard errors represented by vertical bars. ${ }^{\text {a,b,c,d }}$ Mean values within a row with unlike letters were significantly different $(P<0.05)$. C, control diet; WB, wild blueberry diet.

of fatty acid synthase was significantly decreased in the liver and AAT of the OZR and in the AAT of the LZR. Since fatty acid synthase promotes fatty acid synthesis and storage in the adipose tissue, it has been proposed as a possible target for the treatment of the metabolic syndrome ${ }^{(26)}$. Its down-regulation by the WB diet could partly explain the TAG-lowering effect and is consistent with the down-regulation of the expression of SREBP-1 that we observed.

The expression of ABCA1 in the liver was similar in the OZR and LZR and was not affected by WB consumption. In the AAT, the WB diet significantly up-regulated the expression of ABCA1 in both the OZR and LZR. By increasing cholesterol efflux and apoA1-mediated reverse cholesterol transport ${ }^{(27)}$, the up-regulation of the expression of ABCA1 could play a significant role in the cholesterol-lowering effect that we documented in the OZR following the consumption of the WB diet.

The expression of the above-mentioned enzymes and the balance between lipid anabolism and catabolism, in general, are regulated by the activity of transcription factors such as SREBP and PPAR. The modulation of these elements is the target of important lipid-lowering medications such as fibrates (PPAR $\alpha$ agonists) and thiazolidinedione (PPAR $\gamma$ agonists), but it has also been reported to be associated with dietary bioactive compounds including anthocyanins ${ }^{(12)}$.

SREBP-1 isoforms promote the synthesis and accumulation of TAG and cholesterol via the induction of multiple enzymes ${ }^{(28)}$. In mice fed an anthocyanin-rich purple-coloured 'corn' diet for 2 weeks in addition to either a standard or a high-fat diet, the expression of genes involved in fatty acid and TAG synthesis was down-regulated, including fatty acid synthase and SREBP-1 in the adipose tissue ${ }^{(13)}$. In the present study, the expression of SREBP-1 was significantly higher in the OZR than in the LZR and was down-regulated in the OZR following WB consumption in both the liver and AAT. The down-regulation of the expression of SREBP-1 could partly explain the reduction in circulating TAG and cholesterol concentrations that was observed in the OZR following the consumption of the WB diet. The activation of PPAR $\alpha$ also helps to explain such an effect on lipid profiles, since $\operatorname{PPAR} \alpha$ promotes lipid catabolism by up-regulating the expression of a variety of enzymes involved in fatty acid cellular uptake and $\beta$-oxidation, including LPL, acyl-CoA oxidase and acyl-CoA dehydrogenase ${ }^{(29)}$. The consumption of the WB diet significantly up-regulated the expression of PPAR $\alpha$ in the AAT of both the LZR and OZR.

The expression of PPAR $\gamma$ in the AAT was similar in the LZR and OZR and was significantly up-regulated in both the groups following the consumption of the WB diet. PPAR $\gamma$ is primarily expressed in the adipose tissue and controls adipocyte differentiation and insulin sensitivity, by up-regulating the expression of GLUT as well as a variety of genes involved in insulin signalling ${ }^{(30)}$. Similar effects were observed in the AAT and skeletal muscle of OZR fed a $2 \%$ highbush blueberry diet for 13 weeks, resulting in increased PPAR $\alpha$ and PPAR $\gamma$ activity and mRNA expression ${ }^{(14)}$. 
The dual PPAR agonistic effect observed on WB consumption is a positive outcome in the context of the metabolic syndrome, allowing to combine the lipid-lowering effects of PPAR $\alpha$ up-regulation with the improved glucose tolerance associated with PPAR $\gamma$ activity.

Besides controlling lipid metabolism, the activation of both PPAR $\alpha$ and PPAR $\gamma$ also has a strong anti-inflammatory effect, probably via the down-regulation of NF- $\mathrm{B}$ activity ${ }^{(31)}$. Indeed, we have previously documented that a WB diet resulted in a significant attenuation of the expression of NF- $\mathrm{KB}$ in the liver of both LZR and OZR and decreased the levels of inflammation as measured by circulating concentrations and genetic expression of inflammatory markers including IL-6 and TNF $\alpha^{(32)}$.

It should be noted that the present study evaluated the effects of the whole berry and at this point we are not able to determine the specific contribution of the polyphenols, fibre or other bioactive compounds of the berry to the observed effects.

In conclusion, 8-week WB consumption appears to have a positive impact on lipid profiles in dyslipidaemic OZR, with significant reductions in serum TAG and TC concentrations with the maintenance of beneficial HDL-cholesterol concentrations. Wild blueberry consumption also appears to positively affect the expression of key enzymes and transcription factors involved in lipid and cholesterol metabolism, thus reducing risk factors associated with the metabolic syndrome and its progression to type 2 diabetes and CHD.

\section{Acknowledgements}

The present study was supported by the Wild Blueberry Association of North America (WBANA) and Maine Agricultural and Forest Experiment Station (publication no. 3300).

S. V. and D. K.-Z. designed the research. S. V., A. D. and A. S. K. conducted the research. S. V. and D. K.-Z. wrote the paper. All authors read and approved the final manuscript. None of the authors has any conflicts of interest.

\section{References}

1. Roger VL, Go AS, Lloyd-Jones DM, et al. (2012) Heart disease and stroke statistics - 2012 update: a report from the American Heart Association. Circulation 125, e2-e220.

2. Prasad H, Ryan DA, Celzo MF, et al. (2012) Metabolic syndrome: definition and therapeutic implications. Postgrad Med 124, 21-30.

3. Leão LS, de Moraes MM, de Carvalho GX, et al. (2011) Nutritional interventions in metabolic syndrome: a systematic review. Arq Bras Cardiol 97, 260-265.

4. De Artiñano A \& Castro M (2009) Experimental rat models to study the metabolic syndrome. Br J Nutr 9, 1246-1253.

5. Frisbee JC \& Delp MD (2006) Vascular function in the metabolic syndrome and the effects on skeletal muscle perfusion: lessons from the obese Zucker rat. Essays Biochem 42, $145-161$.

6. Häkkinen SH \& Törrönen AR (1999) Screening of selected flavonoids and phenolic acids in 19 berries. J Food Res Int 32, 345-353.
7. Norton C, Kalea AZ, Harris PD, et al. (2005) Wild blueberry rich diets affect the contractile machinery of the vascular smooth muscle in the Sprague-Dawley rat. J Med Food $\mathbf{8}$, $8-13$.

8. Kristo AS, Kalea AZ, Schuschke DA, et al. (2010) A wild blueberry-enriched diet (Vaccinium angustifolium) improves vascular tone in the adult spontaneously hypertensive rat. J Agric Food Chem 58, 11600-11605.

9. Wei X, Wang D, Yang Y, et al. (2011) Cyanidin-3-O- $\beta$-glucoside improves obesity and triglyceride metabolism in KK-Ay mice by regulating lipoprotein lipase activity. J Sci Food Agric 91, 1006-1013.

10. Tsuda T, Ueno Y, Kojo H, et al. (2005) Gene expression profile of isolated rat adipocytes treated with anthocyanins. Biochim Biophys Acta 1733, 137-147.

11. Xia M, Hou M, Zhu H, et al. (2005) Anthocyanins induce cholesterol efflux from mouse peritoneal macrophages: the role of the peroxisome proliferator-activated receptor$\gamma$-liver X receptor- $\alpha$-ABCA1 pathway. $J$ Biol Chem 280, 36792-36801.

12. Seymour EM, Singer AA, Kirakosyan A, et al. (2009) Altered hyperlipidemia, hepatic steatosis, and hepatic peroxisome proliferator-activated receptors in rats with intake of tart cherry. J Med Food 11, 252-259.

13. Tsuda T, Horio F, Uchida K, et al. (2003) Dietary cyanidin 3-O-beta-D-glucoside-rich purple corn color prevents obesity and ameliorates hyperglycemia in mice. $J$ Nutr 133, $2125-2130$

14. Seymour EM, Tanone Urcuyo-Ll II, anes DE, et al. (2011) Blueberry intake alters skeletal muscle and adipose tissue peroxisome proliferator-activated receptor activity and reduces insulin resistance in obese rats. $J$ Med Food 14, 1511-1518.

15. Del Bo' C, Ciappellano S, Klimis-Zacas D, et al. (2010) Anthocyanin absorption, metabolism, and distribution from a wild blueberry-enriched diet (Vaccinium angustifolium) is affected by diet duration in the Sprague-Dawley rat. J Agric Food Chem 58, 2491-2497.

16. Singleton VL, Orthofer R \& Lamuela-Ravent RM (1999) Analysis of total phenols and other oxidation substrates and antioxidants by means of Folin-Ciocalteu reagent. Methods Enzymol 299, 152-178.

17. AOAC Method 991.43 (1995) Total, Insoluble and Soluble Dietary Fiber in Food - Enzymatic-Gravimetric Method, MES-TRIS Buffer. Official Methods of Analysis, 16th ed. Gaithersburg, MD: AOAC International.

18. Vendrame S, Guglielmetti S, Riso P, et al. (2011) Six-week consumption of a wild blueberry powder drink increases bifidobacteria in the human gut. J Agric Food Chem 59, 12815-12820.

19. Reagan-Shaw S, Nihal M \& Ahmad N (2007) Dose translation from animal to human studies revisited. FASEB $J \mathbf{2 2}$ 659-661.

20. Livak KJ \& Schmittgen TD (2001) Analysis of relative gene expression data using real-time quantitative PCR and the Delta Delta CT method. Methods 25, 402-408.

21. Kalt W, Foote K, Fillmore SA, et al. (2008) Effect of blueberry feeding on plasma lipids in pig. BrJ Nutr 100, 70-78.

22. Basu A, Du M, Leyva MJ, et al. (2010) Blueberries decrease cardiovascular risk factors in obese men and women with metabolic syndrome. J Nutr 140, 1582-1587.

23. Riso P, Klimis-Zacas D, Del Bo' C, et al. (2012) Effect of a wild blueberry (Vaccinium angustifolium) drink intervention on markers of oxidative stress, inflammation and endothelial function in humans with cardiovascular risk factors. Eur J Nutr 52, 949-961. 
24. Zhu Y, Ling W, Guo $\mathrm{H}$, et al. (2012) Anti-inflammatory effect of purified dietary anthocyanin in adults with hypercholesterolemia: a randomized controlled trial. Nutr Metab Cardiovasc Dis (Epublication ahead of print version 17 August 2012).

25. Wang H \& Eckel RH (2009) Lipoprotein lipase: from gene to obesity. Am J Physiol Endocrinol Metab 297, e271-e288.

26. Griffin MJ \& Sul HS (2004) Insulin regulation of fatty acid synthase gene transcription: roles of USF and SREBP-1c. IUBMB Life 56, 595-600.

27. Soumian S, Albrecht C, Davies AH, et al. (2005) ABCA1 and atherosclerosis. Vasc Med 10, 109-119.

28. Horton JD, Goldstein JL \& Brown MS (2002) SREBPs: activators of the complete program of cholesterol and fatty acid synthesis in the liver. J Clin Invest 109, 1125-1131.
29. Fruchart JC (2009) Peroxisome proliferator-activated receptor alpha (PPAR- $\alpha)$ : at the crossroads of obesity, diabetes and cardiovascular disease. Atherosclerosis 205, 1-8.

30. Takano H \& Komuro I (2009) Peroxisome proliferator-activated receptor- $\gamma$ and cardiovascular diseases. Circ J 73, 214-220.

31. Poynter ME \& Daynes RA (1998) Peroxisome proliferatoractivated receptor- $\alpha$ activation modulates cellular redox status, represses nuclear factor-kappaB signaling, and reduces inflammatory cytokine production in aging. $J$ Biol Chem 273, 32833-32841.

32. Vendrame S, Daugherty A, Kristo AS, et al. (2012) Wild blueberry consumption markedly attenuates concentration and expression of inflammatory markers in the obese Zucker rat. FASEB J 26, 385.5. 